\title{
Efficacy and Safety of Ombitasvir, Paritaprevir and Ritonavir plus Ribavirin in Hepatitis C Genotype-4 Patients on Hemodialysis
}

\author{
Mai M. Naguib ${ }^{* a}$, Ashraf A. Mahmoud ${ }^{a}$, Sara M. Shaheen ${ }^{b}$, Nagwa A. Sabri ${ }^{\text {b }}$ \\ ${ }^{a}$ Department of Gastroenterology and Hepatology, El-Maadi Armed Forces Hospital, Cairo, Egypt \\ ${ }^{\mathrm{b}}$ Department of Clinical Pharmacy, Faculty of Pharmacy, Ain Shams University, Cairo 11566, Egypt
}

\begin{abstract}
The ongoing standard treatment for patients with chronic hepatitis $\mathrm{C}$ virus (HCV) is a mixture of direct-acting antiviral agents (DAAs). This study aims to analyze the efficacy and safety of oral interferon-free regimen of ombitasvir (OBV), and paritaprevir (PTV) with ritonavir (R) (Qurevo (Q)), given with or without ribavirin (RBV) for chronic hepatitis C Genotype-4 (GT4) patients with or without compensated cirrhosis and experiencing longterm hemodialysis (HD). The study was a prospective, cohort, open-label pilot trial. Fifty patients were recruited and only 47 patients completed the study. All patients were given OBV $25 \mathrm{mg}$, PTV $150 \mathrm{mg}$, and R $100 \mathrm{mg}(2 \mathrm{X} \mathrm{Q}$ capsules) in combination with $200 \mathrm{mg}$ of RBV daily for 12 weeks. Primary endpoints were SVR12 (HCV-RNA <25 $\mathrm{IU} / \mathrm{mL}$ ), reporting of withdrawal rate due to the abundance of any adverse effects and/or side effects in patients receiving at least 1 dose of the study drug. Out of the fifty patients who contributed to the study, only forty-four (88\%) patients achieved SVR12. Three patients $(6 \%)$ discontinued the Q; one experienced interaction with valsartan, one suffered fatigue, severe HTN, dyspnea, and severe anemia, and the last was infected with pneumonia. $\mathrm{Q}$ resistance rate after therapy was $(6 \%)$. On the other hand, the withdrawal rate of RBV was $31.5 \%$ among patients who received the Q-RBV combination. In Conclusion, A 12-week administration of Q with or without RBV is highly effective with an appropriate safety profile amongst GT4 hepatitis C with or without compensated cirrhosis patients with HD.
\end{abstract}

Keywords: Hemodialysis; genotype 4; hepatitis C virus; Qurevo; cirrhosis.

*Correspondence | Mai M. Naguib; Department of Gastroenterology and Hepatology, El-Maadi Armed Forces Hospital, Cairo, Egypt. Email: dr_mai_elshishiny@hotmail.com

Citation | Naguib MM, Mahmoud AA, Shaheen SM, Sabri NA, 2020. Efficacy and Safety of Ombitasvir, Paritaprevir, and Ritonavir plus Ribavirin in Hepatitis C Genotype-4 Patients on Hemodialysis. Arch Pharm Sci ASU 4(2): 181-193

DOI: $10.21608 /$ aps.2020.35940.1037

Print ISSN: 2356-8380. Online ISSN: 2356-8399.

Received 21 July 2020. Accepted 07 September 2020.

Copyright: ${ }^{{ }^{2}} 2020$ Naguib et al. This is an open-access article licensed under a Creative Commons Attribution 4.0 International License (CC BY 4.0), which permits unrestricted use, distribution, and reproduction in any medium, provided the original author(s) and source are credited. Published by: Ain Shams University, Faculty of Pharmacy

\section{INTRODUCTION}

About 71 million individuals worldwide are affected with chronic HCV infection as it is a wide-ranging health problem; in Egypt, approximately 6-8 million individuals are chronically infected with HCV GT4 and at risk of advanced complications (cirrhosis, progression to liver failure, and hepatocellular carcinoma) $[1,2]$.
The aim of HCV treatment is HCV-RNA clearance from serum, which reduces the risk of the serious complications of the disease and explains an effective virological therapy for all patients [3]. GT4 infections make up about 93\% of all chronic HCV patients in Egypt; however, it accounts for $13-20 \%$ of all HCV infections worldwide [4]. 
Remedying options for GT4-infected patients in the generation of DAA therapies for $\mathrm{HCV}$, have expanded to interferon (IFN)-free regulations with or without $\mathrm{RBV}$, including elbasvir/grazoprevir [5], glecaprevir/pibrentasvir [6, 7], Q [8, 9], sofosbuvir (SOF) [10], SOF plus daclatasvir (DCV) [11], SOF plus simeprevir [12], SOF/ledipasvir (LDV) [13], and $\mathrm{SOF} /$ velpatasvir [14]. A nonstructural protein 5A (NS5A) inhibitor OBV and PTV is an NS3/4A inhibitor co-dosed with R. After the last dose of the study drug, high SVR12 rates were achieved in HCV GT4-infected patients without cirrhosis or with compensated cirrhosis treated with Q plus RBV for 12 weeks duration, in the phase $2 b / 3$ PEARL-I 10 and AGATE-I $[\mathbf{8 , 1 5}$ studies. The relation between $\mathrm{HCV}$ infection and kidney disease is well detected [16].

In a large population-based study in Taiwan, the currency of CKD was $16.5 \%$ among those who are seropositive for $\mathrm{HCV}$, and CKD was developed related to chronic $\mathrm{HCV}$ infection which was found to be an independent risk factor [16-18]. In another study, renal disease progression with a higher rate of positive anti$\mathrm{HCV}$ in those with more severe stages of CKD was a result of the presence of anti-HCV antibodies [19].

In all $91 \mathrm{HCV}$ treatment-naïve patients or pegylated IFN plus RBV treatment-experienced patients with GT4 infection, the DAA combination of $\mathrm{Q}$ plus RBV has achieved SVR12, although all patients were recruited outside Egypt and none had cirrhosis [9]. This administration accomplished SVR12 in 40 (91\%) of 44 patients without $\mathrm{RBV}$, and in some countries is an approved therapy option for patients unable to tolerate RBV [9]. Based on these data, the European approved this regimen for patients with cirrhosis, in Egypt, this regimen was used for a 12-week treatment duration of patients with GT4 infection without cirrhosis and 24-week treatment duration with compensated cirrhosis. So, this study aimed to evaluate the efficacy and safety of the oral regimen free of IFN of $Q$, given with or without RBV based treatment in $\mathrm{HCV}$ treatment naïve patients on long-term HD for chronic HCV-GT4 with or without compensated cirrhosis.

Adverse reactions of this protocol "Qurevo" are well tolerated. As reported by El-Fishawy et al., one-third of patients complain of fatigue. Less common side effects include skin reactions, myalgias, nausea, and insomnia. Hyperbilirubinemia with $>5$ fold-elevation of hepatic transaminases occurs in $1 \%$ of cases, yet up to $25 \%$ in women receiving estrogen therapy. While this is usually transient, progression to severe hepatic failure has been reported in patients with advanced cirrhosis, which warranted a relevant FDA warning [20].

Regarding RBV adverse reactions, since many protocols include RBV, its significant side effects may be superadded to those of the individual protocols. RBV administration, by its right, is associated with fatigue in about two-thirds of cases, headache in one half, and insomnia, irritability, fever, nausea, and dermatitis in onethird. Less common side effects include arthralgias and myalgias, dizziness, diarrhea, and shortness of breath. Owing to its retention in patients with impaired kidney function, many of these side effects are augmented, in addition to the development of Coombs negative hemolytic anemia that can be very severe in CKD Stages IV-V [20].

Reported pharmacodynamic interactions of Q was restricted to increased risk of adverse reactions and ALT elevations when coadministrated with enzyme inducers. Regarding pharmacokinetic interactions potential for $\mathrm{Q}$ to affect the pharmacokinetics of other drugs due to the presence of ritonavir which is a strong inhibitor of CYP3A. Co-administration of Q with 
medications primarily metabolized by CYP3A may result in increased plasma concentrations of them. So those that are highly dependent on CYP3A for clearance and for which elevated plasma levels are associated with serious events are contraindicated. Paritaprevir is an inhibitor of the hepatic uptake transporters OATP1B1 and OATP1B3, and paritaprevir and ritonavir are inhibitors of OATP2B1. Ritonavir is an in vitro inhibitor of OCT1, but the clinical relevance is unknown. Co-administration of $\mathrm{Q}$ with drugs that are substrates of OATP1B1, OATP1B3, OATP2B1, or OCT1 may increase plasma concentrations of these transporter substrates, potentially requiring dose adjustment/clinical monitoring. Examples of these medications include some statins, fexofenadine, repaglinide, and angiotensin II receptor antagonists (e.g., valsartan) [21].

\section{PATIENTS AND METHODS}

\subsection{Ethics}

The protocol of the study was approved by the ethics committee of faculty of pharmacy, Ain Shams University, and the ethics committee of Al-Maadi armed forces hospital, and written informed consent was presented and signed by each participant before sharing in the study. The study was registered on clinicaltrial.gov under ID: NCT03067883.

\subsection{Study setting and design}

The study design was a prospective, cohort, open-label pilot clinical trial conducted on 50 HCV treatment naïve patients (recruited from AlMaadi armed forces hospital); with or without compensated cirrhosis on scheduled HD, fulfilling the inclusion and exclusion criteria of the study protocol, to evaluate of the ratio of patients with an SVR (HCV-RNA $<25 \mathrm{IU} / \mathrm{mL}$ ) to assess the efficacy and safety of $\mathrm{Q}$ based treatment for chronic $\mathrm{HCV}$ with or without compensated cirrhosis.

\subsection{Treatment Intervention}

These patients received $25 \mathrm{mg}$ of OBV, 150 $\mathrm{mg}$ of PTV, and $100 \mathrm{mg} \mathrm{R}$ (2X Q capsules) plus $200 \mathrm{mg}$ of RBV daily for 12 weeks. Drugs' regimen was as follows; Two hard gelatin capsules of $\mathrm{Q}$ was given one time daily (on the dialysis day after the dialysis period), RBV was given one time daily (on the dialysis day, 4 hours before the dialysis session) which was stopped in those who seasoned a descend in serum hemoglobin $(\mathrm{Hb})>2 \mathrm{~g} / \mathrm{dL}$ after one month of RBV administration, or had any hemoglobin ratio (Hb) $<8 \mathrm{~g} / \mathrm{dL}$ during the whole study period until resuming their normal $\mathrm{Hb}$ levels where $\mathrm{RBV}$ has introduced again in the same regimen. Followingup of patients was done for a period of 24 weeks.

\subsection{Patient Eligibility}

Patients were included in the study if they were male or female patients age 18 to 70 years old, under scheduled HD for at least 6 months, clinically steady condition as outpatients, treatment candid patients with serum positive for HCV GT4 with HCV-RNA > $1000 \mathrm{IU} / \mathrm{mL}$ by PCR, white blood cell count $>2500 / \mathrm{mm}^{3}$, platelet count $>7500 / \mathrm{mm}^{3}$, and patients categorized as suffering from compensated cirrhosis had a recognition of cirrhosis based on an earlier screening liver Fibro-Test score of 0.72 or lower (e.g. Metavir Fibrosis Score $>3$ [including 3/4 or 3-4])

Patients were excluded if the pregnancy was confirmed, had co-infection of HCV-HIV, coinfection of $\mathrm{HBV}-\mathrm{HCV}$, unrestrained hyper or hypothyroidism, or on peritoneal dialysis. Patients without cirrhosis were proscribed if alanine or aspartate aminotransferase $>$ five times the upper limit of normal and those with cirrhosis were proscribed if alanine or aspartate aminotransferase > seven times the upper limit of normal. 


\subsection{Baseline data}

Patients' demographic data, full medication, medical history, and laboratory data were collected comprehending; complete blood picture, tests for liver function, tests for renal function, T3 and T4, alfa-fetoprotein (AFP), quantitative $\mathrm{HCV}$ viremia (HCV-RNA), and screening Fibro-Test score.

\subsection{Endpoints and Follow up data}

The principal efficacy endpoint was the proportion of patients accomplishing an SVR 12 explained as (HCV-RNA $<25 \mathrm{IU} / \mathrm{mL}) 12$ weeks after the last dose of study drug (SVR12).

Subsidiary efficacy endpoints included; End of Treatment (EOT) virologic response, defined as $(\mathrm{HCV}-\mathrm{RNA}<25 \mathrm{IU} / \mathrm{Ml})$ measured at the EOT, withdrawal rate related to adverse effects and/or side effects for patients receiving at least 1 dose of the study drug, and virologic response including relapse (HCV-RNA $\geq$ LLOD) during any follow-up post-treatment visit in patients with (HCV-RNA<LLOD) at the EOT, virologic nonresponse (HCV-RNA $\geq$ LLOD at EOT).

\subsection{Patients follow up}

Patients were followed up at the nephrology and hepatology departments of the hospital for the whole study period, 24 weeks, where all previous laboratory tests, quantitative PCR for HCV-RNA testing were assessed every month during therapy, 3 and 6 months after the end of treatment, and anti-HCV antibody every three months during therapy and at 3 and 6 months after the EOT.

\subsection{Adverse effects reporting}

Patients were educated about the adverse effects and /or side effects of the therapy given to them and were asked to report any undesirable effects once detected throughout the trial by contacting the research team.

\subsection{Statistical Analysis}

Statistics entry, processing, and statistical analysis were implemented using MedCalc ver. 15.8. Significance tests (Chi-square, Mann Whitney's test, Friedman's, repeated measures ANOVA and Kaplan-Meier survival curve) were used. Data was demonstrated and acceptable analysis was done consistent with the type of data (parametric and non-parametric) obtained for each variable. $\mathrm{P}$-values $<0.05$ were regarded to be statistically significant. Results were analyzed using the intent-to-treat approach.

\section{RESULTS}

In this study, a total of 50 patients participated in the study; but only forty-seven completed the study protocol. The causes of withdrawal were as follows: one patient couldn't take Q after 1 month because he was infected with pneumonia, one had HTN and suffered drug-drug interaction with valsartan According to literature, drug interaction of $\mathrm{Q}$ with valsartan is reported to be of a moderate clinical significant and clinical monitoring with dose adjustment was recommended if valsartan is co-administered with $\mathrm{Q}$, although these recommendations were taken into account this patient couldn't tolerate the adverse effects of this interaction and accordingly was withdrawn from the study. The last patient was withdrawn as he suffered untolerated side effects in the form of fatigue, severe HTN, dyspnea, and severe anemia). Baseline demographic and clinical data are represented (Table 1).

Regarding treatment, it was found that the majority of patients (76\%) were compliant to the combination of Q-RBV all over the study period; while the rest of the patients $(24 \%)$ discontinued RBV due to unacceptable $\mathrm{Hb}$ levels. The average duration of RBV administration was $(2.52 \pm 0.76)$ months compared to $(2.88 \pm 0.47)$ months for $\mathrm{Q}$. Moreover, it was found that the $\mathrm{Q}$ withdrawal rate was $6 \%$ among patients, while $31.5 \%$ was the RBV withdrawal rate among the Q-RBV group as shown in (Table 2). 
Table 1. Demographic and clinical data among the 50 hepatic patients

\begin{tabular}{|c|c|c|}
\hline \multicolumn{2}{|l|}{ Variables } & \multirow{2}{*}{$\begin{array}{l}\text { Patients included in the study } \\
\qquad \mathbf{N}=\mathbf{5 0} \\
48.12 \pm 15.42\end{array}$} \\
\hline Age (years) & mean $\pm \mathrm{SD}$ & \\
\hline \multirow{2}{*}{ Sex } & Female patients $\mathrm{n}(\%)$ & $24(48 \%)$ \\
\hline & Male patients $\quad \mathrm{n}(\%)$ & $26(52 \%)$ \\
\hline BMI & mean $\pm \mathrm{SD}$ & $27.66 \pm 4.45$ \\
\hline \multicolumn{2}{|c|}{ Metavir fibrosis score median(Range) } & $1.5(0-4)$ \\
\hline \multicolumn{2}{|c|}{ Child-Pugh score median (Range) } & $6(5-8)$ \\
\hline \multirow{2}{*}{ Cirrhosis } & Non-cirrhotic $\mathrm{n}(\%)$ & $29(58 \%)$ \\
\hline & Cirrhotic $\mathrm{n}(\%)$ & $21(42 \%)$ \\
\hline \multirow{2}{*}{ HTN } & Normal $\mathrm{n}(\%)$ & $29(58 \%)$ \\
\hline & Hypertensive $\mathrm{n}(\%)$ & $21(42 \%)$ \\
\hline \multirow[t]{2}{*}{ DM } & Normal n (\%) & $34(68 \%)$ \\
\hline & Diabetic $\mathrm{n}(\%)$ & $16(32 \%)$ \\
\hline
\end{tabular}

BMI: body mass index, HTN: hypertension, DM: diabetes mellitus.

Table 2. Drug usage data among the 50 hepatic patients

\begin{tabular}{lll}
\hline Variables & & Mean \pm SD/N (\%) \\
\hline Ribavirin usage & Q-RBV group & $38(76) \%$ \\
Qurevo usage & Q group & $12(24) \%$ \\
Ribavirin duration (months) & Q-RBV group & $50(100) \%$ \\
Qurevo duration (months) & Q-RBV group (38) & $2.52 \pm 0.76$ \\
Ribavirin withdrawal rate & Q-RBV group (38) & $2.88 \pm 0.47$ \\
Qurevo withdrawal rate & Q-RBV group (38) & $12 / 38(31.5) \%$ \\
Ribavirin withdrawal duration (months) & Q-RBV group (38) & $3(6) \%$ \\
Qurevo withdrawal duration (months) & Q-RBV group (38) & $1.54 \pm 0.52$ \\
\hline
\end{tabular}

Q-RBV: "Qurevo \& Ribavirin" regimen, Q: "Qurevo only" regimen. 
Regarding efficacy endpoints, EOT virologic response, SVR 12 and 24 rates at 3 and 6-months assessments were $(88 \%)$, while $3(6 \%)$ patients showed virologic nonresponse and no relapse (HCV-RNA $\geq$ LLOD) during any follow-up posttreatment visit in patients with (HCVRNA<LLOD) at the EOT was observed as shown in (Table 3).

When patients were further stratified into cirrhotic (42\%) and non-cirrhotic (58\%), cirrhotic patients exhibited more prevalence for DM than non-cirrhotic patients with significant difference $(\mathrm{P}=0.031)$; while there were comparable results between patients with cirrhosis and non-cirrhosis as regards sex and HTN (P>0.05) "data not presented"

According to their Metavir fibrosis score, a non-significant difference was found between the two groups with $(\mathrm{P}>0.05)$ regarding $\mathrm{RBV}, \mathrm{Q}$ usage, withdrawal rates; and SVR achievement “ data not presented"

Patients with cirrhosis had a relatively higher average $\mathrm{Hb}, \mathrm{AST}$, ALT, and total bilirubin during serial laboratory measurements; but in both groups, Hb levels were increased while AST, ALT, and bilirubin levels were decreased (especially during 3rd and 6th months follow up after Q treatment) with high significant difference $(\mathrm{P}<0.05)$. The remaining variables were comparable $(\mathrm{P}>0.05)$ in both groups (Table 4).

Survival analysis (regarding the achievement of SVR) was conducted with "Kaplan-Meier survival analysis" and results showed increased observed SVR events over expected events (O/E ratio=1.12); with mean survival time of 3 months; and a significant difference was found between the 2 survival curves (Log-rank test $\mathrm{P}=0.0001$ ) as shown in Fig. 1.

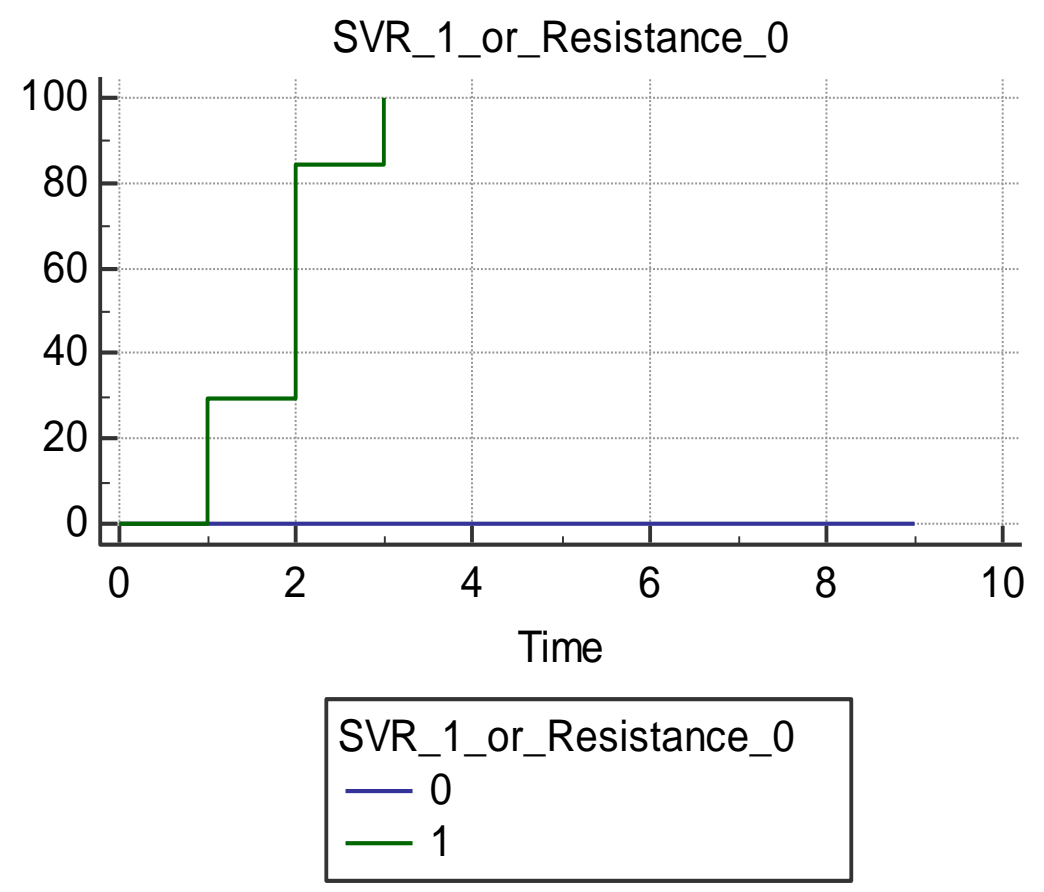

Fig. 1. Kaplan-Meier survival curve showing increased survival probability starting from 2nd month of $Q$ therapy with high significant difference (Log rank test $P=0.0001)$ 
Table 3. Sustained Virologic Response after Qurevo therapy (3 and 6 months follow up) among the 50 hepatic patients

\begin{tabular}{lll}
\hline Outcome & $\begin{array}{c}\text { SVR (3 month) } \\
\text { After therapy } \\
\mathbf{N}(\%)\end{array}$ & $\begin{array}{l}\text { SVR (6 month) } \\
\text { after therapy } \\
\text { N (\%) }\end{array}$ \\
\hline $\begin{array}{l}\text { Achieved } \\
\text { (Qurevo SVR) }\end{array}$ & $44(88) \%$ & $44(88) \%$ \\
$\begin{array}{l}\text { Not achieved } \\
\text { (Qurevo resistance after therapy) }\end{array}$ & $3(6) \%$ & $3(6) \%$ \\
$\begin{array}{l}\text { Not achieved } \\
\text { (Qurevo withdrawal during therapy) }\end{array}$ & $3(6) \%$ & $3(6) \%$ \\
\hline
\end{tabular}

Table 4. Comparability between cirrhotic (21) and non-cirrhotic (29) patients using repeated measures ANOVA test (2-Factor study) related to serial 6 laboratory measurements

\begin{tabular}{lcc}
\hline & \multicolumn{2}{c}{ Repeated 6 measures ANOVA } \\
Investigations & (2-F: between cirrhotic and non-cirrhotic) & p value \\
\hline AFP $(\mathrm{ng} / \mathrm{mL})$ & F value & $=0.147$ \\
$\mathrm{~T}_{3}(\mathrm{ng} / \mathrm{dL})$ & 2.17 & $=0.052$ \\
$\mathrm{~T}_{4}(\mathrm{ng} / \mathrm{dL})$ & 4.36 & $=0.578$ \\
Creatinine $(\mathrm{mg} / \mathrm{dL})$ & 0.31 & $=0.223$ \\
$\mathrm{Hb}(\mathrm{g} / \mathrm{dL})$ & 1.53 & $=0.048^{*}$ \\
$\mathrm{Platelets}\left(10^{3} / \mu \mathrm{L}\right)$ & 4.13 & $=0.749$ \\
$\mathrm{TLC}\left(10^{3} / \mu \mathrm{L}\right)$ & 0.10 & $=0.429$ \\
$\mathrm{AST}(\mathrm{U} / \mathrm{L})$ & 0.64 & $=0.001^{*}$ \\
$\mathrm{ALT}(\mathrm{U} / \mathrm{L})$ & 12.35 & $=0.006^{*}$ \\
Albumin $(\mathrm{g} / \mathrm{dL})$ & 8.44 & $=0.082$ \\
$\mathrm{INR}$ & 3.16 & $=0.075$ \\
Total bilirubin $(\mathrm{mg} / \mathrm{dL})$ & 3.31 & $=0.013^{*}$ \\
HCV RNA $(\mathrm{PCR})(\mathrm{U} / \mathrm{mL})$ & 6.75 & $=0.198$ \\
\hline
\end{tabular}

ANOVA: analysis of variance, 2-F: 2-factor study. \#logarithmic transformation was done to non-parametric data.

* : statistically significant. 


\section{DISCUSSION}

Before the generation of IFN-free treatment regimens, due to the toxicity and poor tolerability of the available regimens, few $\mathrm{HCV}$-infected patients with ESRD experienced HCV treatment. As such, these patients have not benefitted from $\mathrm{HCV}$ therapy and have remained at risk for progression of liver disease, including cirrhosis, and hepatocellular carcinoma complications, and death [22]. The approval of new DDA agents for $\mathrm{HCV}$ dramatically changed the treatment approach in $\mathrm{HCV}$-infected patients with mild, moderate, and renal impairment [23]. OBV, PTV, DSV, and R are all hepatically metabolized with minimal renal clearance, the pharmacokinetics of these DAAs were evaluated in HCV seronegative persons with mild, moderate, and severe renal impairment and the plasma exposures observed supports use of this regimen in $\mathrm{HCV}$-infected patients with renal impairment with no need for dose adjustments [24].

In the current study, serial laboratory measurements (baseline, during, and after Q therapy); of the $50 \mathrm{HCV}$, infected patients revealed that; the average AFP levels were increased during serial 6 measurements (but within normal range). These results came in disagreement with Atsukawa and his co-workers; who reported that, after the beginning of treatment and post 12 weeks, the AFP levels declined from baseline [25]. This may be attributed to a higher percentage of cirrhotic patients $(42 \%)$ in this study compared to only $(30 \%)$ in the Atsukawa study which can represent a risk for the elevation of AFP.

On the other hand, in this study, the Hb levels at the $1^{\text {st }}$ and $2^{\text {nd }}$ months were reduced than increased significantly $(\mathrm{P}<0.05)$. This can be explained by RBV usage duration, where after its withdrawal the average level of $\mathrm{Hb}$ was increased significantly.
The results obtained in this work showed that the average platelets, TLC, albumin, and total bilirubin levels were increased significantly after 3 and 6 months with $\mathrm{Q}$ therapy $(\mathrm{P}<0.05)$ which were in agreement with those results reported by Muñoz-Gómez and his colleagues, where, TLC and platelets levels were normalized after treatment [26]. Moreover, the average AST and ALT levels were decreased significantly after the three and six months for $\mathrm{Q}$ therapy $(\mathrm{P}<0.05)$ as those reported by Abad and her co-workers that liver enzymes were significantly decreased after treatment with Q from $24.2 \pm 16.7$ to $14.7 \pm 4.4 \mathrm{U} / \mathrm{L}$ $(\mathrm{P}=0.008)$ [27]. This confirms the expected outcome which is the normalization of $\mathrm{CBC}$ components and liver enzyme levels after achieving SVR with the used antiviral regimen.

Regarding drug usage data, the study results revealed that; the majority of patients $(76 \%)$ received "Q-RBV" combined regimen; while the rest of patients $(24 \%)$ received " $Q$ therapy only" regimen. The average RBV usage duration was $(2.52 \pm 0.76)$ months. The RBV withdrawal rate was $(31.5 \%)$ among the Q-RBV group; with an average withdrawal duration of $(1.54 \pm 0.52)$ months, while the $\mathrm{Q}$ withdrawal rate was $(6 \%)$ due to untolerated side effects among all 50 patients; with an average withdrawal duration of 1 month. These results came in agreement with Perelló and his co-workers in 2016; who reported that $30(10.3 \%)$ patients experienced serious adverse events, and only $6(2.1 \%)$ patients discontinued the study early [28]. The values reported in the current study and those reported by Perelló et al., are close to those observed in other clinical trials which are good for a clinical practice study. Moreover, the higher withdrawal rate was in those receiving RBV which is also common among the other clinical trials due to the significant drop in Hb levels.

Regarding SVR (SVR 12 and 24) data, the results of the current study found that; SVR 
achievement rate was $88 \%$ at 3 and 6-months assessments. On the other hand, the Q resistance rate after therapy was $6 \%$. These results came in agreement with many studies testing the $Q \pm$ RBV combination in HD patients. First, Schnell and his co-workers in 2015; who reported that, for curing-naive patients receiving $Q$ without RBV, the SVR12 rate for GT4-infected patients was $81.3 \%(13 / 16)$ and for curing-naïve was $100 \%(22 / 22)$ and curing-experienced $100 \%$ (30/30) patients receiving Q with RBV [29]. Also, the SVR rate reported by Asselah and his co-workers in 2016 was accomplished in 57 (97\%) of 59 patients in the 12-week [8]. While, Morisawa and his co-workers in 2017; noticed a decrease in HCV-RNA after the therapy of 12 weeks in the majority of patients recruited while 2 patients did not achieve virus eradication [30]. Moreover, Ferenci and his co-workers in 2019 reported that all subgroups except for patients with Grade 3 renal impairment, had an SVR12 rate of $84 \%$, and marked reduction of HCV RNA collected after treatment [31]. This confirms the efficacy of the $\mathrm{Q} \pm \mathrm{RBV}$ regimen among $\mathrm{HCV}$ infected patients on HD.

It was found that; there were comparable results when patients were further stratified into cirrhotic and non-cirrhotic patients as regards RBV, Q usage and withdrawal rates; and SVR achievement $(\mathrm{P}>0.05)$. These results lead us to the fact that; Q regimen was effective in the achievement of SVR in cirrhotic patients on regular dialysis; along with non-cirrhotic ones. These promising results came in agreement with Flisiak and his co-workers in 2016 who reported that; in difficult-to-treat populaces such as those with liver cirrhosis or null-responders to earlier anti-viral treatments, this regimen proved to be highly noticeable. For patients with liver cirrhosis regardless of their therapy history, SVR12 was accomplished in 98.3\% (117/119) of them [32], also many earlier clinical trials and real-life studies on patients with cirrhosis showed similar results [33-36]. These studies confirm the study findings and support the use of $Q \pm R B V$ in cirrhotic patients on regular dialysis.

Kaplan-Meier survival curve showed increased survival probability started from 2nd month of $\mathrm{Q}$ therapy with high significant difference (Log-rank test $\mathrm{P}=0.0001$ ). It was shown that; increased observed SVR events over expected events $(\mathrm{O} / \mathrm{E}$ ratio=1.12); with a mean survival time of 1.8 months; with a highly significant difference between the 2 survival curves (Log-rank test $\mathrm{P}=0.0001$ ). These results came in agreement with Butt and his co-workers in 2017; who reported that in a model limited to those who received treatment, attainment of SVR was associated with significantly lower mortality, as they observed a significant survival benefit with treatment and with the attainment of SVR [37]. This confirms that treatment is associated with a significant survival benefit in these patients.

\section{Conclusion}

Qurevo response rates after (6 months follow up) among 50 hepatic patients; was (88\%); with a resistance rate of $(6 \%)$; and a withdrawal rate of $(6 \%)$.

Also, the Qurevo regimen was effective in the achievement of SVR in cirrhotic patients on regular dialysis; along with non-cirrhotic ones. These results strengthen the usage of Qurevo even in cirrhotic patients on chronic hemodialysis.

Qurevo was safe and tolerable by the patients, no risk was found to patients after being assessed by laboratory testing, physical exam, or monitoring of clinical adverse events, also it did not affect their lifestyle and daily activities.

\section{Recommendations}

Qurevo is recommended for the handling of 
and curing hepatitis C genotype-4 patients on hemodialysis.

\section{Declarations}

\section{Ethics approval and consent to participate}

The study protocol was approved by the ethics committee of faculty of pharmacy, Ain Shams University, and the ethics committee of Al-Maadi armed forces hospital, and written informed consent was presented and signed by each participant before sharing in the study.

The study was registered on clinicaltrial.gov under ID: NCT03067883.

\section{Consent to publish}

"not applicable"

\section{Availability of data and materials}

All data generated and analyzed during this study are included in this published article in the main manuscript.

\section{Competing interests}

"No conflicts of interest have been declared".

\section{Funding Statement}

This research did not receive any specific grant from funding agencies in the public, commercial, or not-for-profit sectors.

\section{Authors' contributions}

All authors have contributed significantly to the publication.

All authors have approved the final article

\section{Acknowledgment}

We would like to thank Maadi Armed Forces Hospital for its support and assistance.

\section{List of abbreviations}

HCV, Hepatitis C Virus; DAAs, Direct Acting Antiviral agents; OBV, Ombitasvir; PTV, Paritaprevir; R, Ritnovir; Qurevo,
Ombitasvir/Paritaprevir/Ritonavir; Q, Qurevo therapy only; RBV, Ribavirin; Q-RBV, Qurevo therapy and Ribavirin; GT4, Genotype 4; HD, Hemodialysis; SVR, Sustained Virological Response; HCV-RNA, Hepatitis C VirusRiboNucleic Acid; HTN, Hypertension; IFN, Interferon; SOF, Sofosbuvir; DCV, daclatasvir; LDV, ledipasvir; NS5A, Non-Structural Protein 5 A; NS3/4A, Non-Structural 3/4 A; CKD, Chronic Kidney Disease; $\mathrm{Hb}$, hemoglobin ; PCR, Polymerase Chain Reaction; HCV-HIN, Hepatitis C Virus - Human Immunodeficiency Virus; HBV-HCV, Hepatitis B Virus - Hepatitis C Virus; T3, Throxine 3 Hormone; T4, Thyroxine 4 Hormone; AFP, Alpha FetoProtein; EOT, End of Treatment; LLOD, Lower Limit Of Detection; ANOVA, Analysis Of Variance; BMI, Body Mass Index; DM, Diabetes Mellitus; AST, Aspartate Amino Transferase; ALT, Alanine Amino Transferase; TLC, Total Lymphocyte Count; INR, International Normalised Ratio (Blood Clotting Test); ESRD, End Stage Renal Disorder

\section{REFERENCES}

1. Gower E, Estes C, Blach S, Razavi-Shearer K, Razavi H. Global epidemiology and genotype distribution of the hepatitis C virus infection. Journal of Hepatology 2014; 61:S45-S57. doi: 10.1016/j.jhep.2014.07.027.

2. Smith DB, Bukh J, Kuiken C, Muerhoff AS, Rice CM, Stapleton JT, et al. Expanded classification of hepatitis $\mathrm{C}$ virus into 7 genotypes and 67 subtypes: updated criteria and genotype assignment web resource. Hepatology 2014; 59:318-327. doi: 10.1002/hep.26744.

3. Messina JP, Humphreys I, Flaxman A, Brown A, Cooke GS, Pybus OG, et al. Global distribution and prevalence of hepatitis $\mathrm{C}$ virus genotypes. Hepatology 2015; 61:77-87. doi: 10.1002/hep.27259.

4. Mahmud S, Al-Kanaani Z, Chemaitelly H, Chaabna K, Kouyoumjian SP, Abu-Raddad LJ. Hepatitis C virus genotypes in the Middle East and North 
Africa: Distribution, diversity, and patterns. Journal of Medical Virology 2018; 90:131-141. doi: 10.1002/jmv.24921.

5. Zeuzem S, Ghalib R, Reddy KR, Pockros PJ, Ari ZB, Zhao Y, et al. Grazoprevir-elbasvir combination therapy for treatment-naive cirrhotic and noncirrhotic patients with chronic hepatitis $\mathrm{C}$ virus genotype 1, 4, or 6 infection: a randomized trial. Annals of Internal Medicine 2015; 163:1-13. doi: 10.7326/M15-0785.

6. Forns X, Lee SS, Valdes J, Lens S, Ghalib R, Aguilar H, et al. Glecaprevir plus pibrentasvir for chronic hepatitis $\mathrm{C}$ virus genotype $1,2,4,5$, or 6 infection in adults with compensated cirrhosis (EXPEDITION-1): a single-arm, open-label, multicentre phase 3 trial. The Lancet Infectious Diseases 2017; 17:1062-1068. doi: 10.1016/S1473-3099(17)30496-6.

7. Kwo PY, Poordad F, Asatryan A, Wang S, Wyles DL, Hassanein $\mathrm{T}$, et al. Glecaprevir and pibrentasvir yield high response rates in patients with HCV genotype 1-6 without cirrhosis. Journal of Hepatology 2017; 67:263-271. doi: 10.1016/j.jhep.2017.03.039.

8. Asselah T, Hézode C, Qaqish RB, ElKhashab M, Hassanein T, Papatheodoridis G, et al. Ombitasvir, paritaprevir, and ritonavir plus ribavirin in adults with hepatitis $C$ virus genotype 4 infection and cirrhosis (AGATE-I): a multicentre, phase 3, randomized open-label trial. The Lancet Gastroenterology \& Hepatology 2016; 1:25-35. doi: 10.1016/S2468-1253(16)30001-2.

9. Hézode C, Asselah T, Reddy KR, Hassanein T, Berenguer M, Fleischer-Stepniewska K, et al. Ombitasvir plus paritaprevir plus ritonavir with or without ribavirin in treatment-naive and treatmentexperienced patients with genotype 4 chronic hepatitis $\mathrm{C}$ virus infection (PEARL-I): a randomized, open-label trial. The Lancet 2015; 385:2502-2509. doi: 10.1016/S01406736(15)60159-3.

10. Ruane PJ, Ain D, Stryker R, Meshrekey R, Soliman M, Wolfe PR, et al. Sofosbuvir plus ribavirin for the treatment of chronic genotype 4 hepatitis $\mathrm{C}$ virus infection in patients of Egyptian ancestry. Journal of Hepatology 2015; 62:10401046. doi: 10.1016/j.jhep.2014.10.044.

11. Babatin MA, Alghamdi AS, Albenmousa A, Alaseeri A, Aljarodi M, Albiladi H, et al. Efficacy and safety of simeprevir or daclatasvir in combination with sofosbuvir for the treatment of hepatitis $\mathrm{C}$ genotype 4 infection. Journal of Clinical Gastroenterology 2018; 52:452-457. doi: 10.1097/MCG.0000000000000896.

12. Ng TI, Krishnan P, Pilot-Matias T, Kati W, Schnell G, Beyer J, et al. In vitro antiviral activity and resistance profile of the next-generation hepatitis $\mathrm{C}$ virus NS5A inhibitor pibrentasvir. Antimicrobial Agents and Chemotherapy 2017; 61:e02558-16. doi: 10.1128/AAC.02558-16.

13. Pilot-Matias T, Tripathi R, Cohen D, Gaultier I, Dekhtyar $\mathrm{T}, \mathrm{Lu} \mathrm{L}$, et al. In vitro and in vivo antiviral activity and resistance profile of the hepatitis $\mathrm{C}$ virus NS3/4A protease inhibitor ABT450. Antimicrobial Agents and Chemotherapy 2015; 59:988-997. doi: 10.1128/AAC.04227-14.

14. Asselah T, Moreno C, Sarrazin C, Gschwantler M, Foster GR, Craxí A, et al. Efficacy of a 12-week Simeprevir plus Peginterferon/ribavirin (PR) regimen in treatment-Naïve patients with hepatitis $\mathrm{C}$ virus (HCV) genotype 4 (GT4) infection and mild-to-moderate fibrosis displaying early ontreatment Virologic response. PloS One 2017; 12:e0168713. doi: 10.1371/journal.pone.0168713.

15. Asselah T, Bourgeois S, Pianko S, Zeuzem S, Sulkowski M, Foster GR, et al. Sofosbuvir/velpatasvir in patients with hepatitis C virus genotypes 1-6 and compensated cirrhosis or advanced fibrosis. Liver International 2018; 38:443-450. doi: 10.1111/liv.13534.

16. Li W-C, Lee Y-Y, Chen I-C, Wang S-H, Hsiao C$\mathrm{T}$, Loke S-S. Age and gender differences in the relationship between hepatitis $\mathrm{C}$ infection and all stages of Chronic kidney disease. Journal of Viral Hepatitis 2014;21:706-715. doi: 10.1111/jvh.12199.

17. El-Serag HB, Hampel H, Yeh C, Rabeneck L. Extrahepatic manifestations of hepatitis $\mathrm{C}$ among 
the United States male veterans. Hepatology 2002; 36:1439-1445. doi: 10.1053/jhep.2002.37191.

18. Chen Y-C, Lin H-Y, Li C-Y, Lee M-S, Su Y-C. A nationwide cohort study suggests that hepatitis $\mathrm{C}$ virus infection is associated with increased risk of chronic kidney disease. Kidney International 2014; 85:1200-1207. doi: 10.1038/ki.2013.455.

19. Lee J-J, Lin M-Y, Yang Y-H, Lu S-N, Chen H-C, Hwang S-J. Association of hepatitis C and B virus infection with CKD in an endemic area in Taiwan: a cross-sectional study. American Journal of Kidney Diseases 2010; 56:23-31. doi: 10.1053/j.ajkd.2010.01.015.

20. El-Fishawy H, Saadi G, Hassaballa M, Hussein M, Doss W, Ragab G, Barsoum R. Antiviral treatment prioritization in $\mathrm{HCV}$-infected patients with extrahepatic manifestations - An Egyptian perspective. Journal of Advanced Research 2016; 7(3):391 402. doi: 10.1016/j.jare.2016.02.006.

\section{AbbVie Deutschland GmbH \& Co. KG. ANNEX I} summary of product characteristics. the European Medicines Agency web site: http://www.ema.europa.eu.

22. Pockros PJ, Reddy KR, Mantry PS, Cohen E, Bennett M, Sulkowski MS, et al. Efficacy of direct-acting antiviral combination for patients with hepatitis $\mathrm{C}$ virus genotype 1 infection and severe renal impairment or end-stage renal disease. Gastroenterology 2016; 150:1590-1598. doi: 10.1053/j.gastro.2016.02.078.

23. Azmi AN, Tan S-S, Mohamed R. Hepatitis C, and kidney disease: an overview and approach to management. World Journal of Hepatology 2015; 7:78. doi: 10.4254/wjh.v7.i1.78.

24. Khatri A, Dutta S, Marbury $\mathrm{T}$, Preston R, Rodrigues-Jr L, Wang $\mathrm{H}$, et al. The Pharmacokinetics and Safety of the Direct-Acting Antiviral Regimen of ABT-450/r, Ombitasvir with/without Dasabuvir in Subjects with Mild, Moderate and Severe Renal Impairment Compared to Subjects with Normal Renal Function: 238. Hepatology 2014; 60. doi: 10.1007/s40262-0160429-9.
25. Atsukawa M, Tsubota A, Koushima Y, Ikegami T, Watanabe K, Shimada N, et al. Efficacy and safety of ombitasvir/paritaprevir/ritonavir in dialysis patients with genotype $1 \mathrm{~b}$ chronic hepatitis C. Hepatology Research 2017; 47:1429-1437. doi: 10.1111/hepr.12910.

26. Muñoz-Gómez R, Rincon D, Ahumada A, Hernández $\mathrm{E}$, Devesa $\mathrm{MJ}$, Izquierdo $\mathrm{S}$, et al. Therapy with ombitasvir/paritaprevir/ritonavir plus dasabuvir is effective and safe for the treatment of genotypes 1 and 4 hepatitis $\mathrm{C}$ virus (HCV) infection in patients with severe renal impairment: a multicentre experience. Journal of Viral Hepatitis 2017; 24:464-471. doi: 10.1111/jvh.12664.

27. Poordad F, Sedghi S, Pockros PJ, Ravendhran N, Reindollar R, Lucey MR, et al. Efficacy and safety of ombitasvir/paritaprevir/ritonavir and dasabuvir with low-dose ribavirin in patients with chronic hepatitis $\mathrm{C}$ virus genotype 1a infection without cirrhosis. Journal of Viral Hepatitis 2019. doi: 10.1111/jvh.13109.

28. Perelló C, Carrión JA, Ruiz-Antorán B, Crespo J, Turnes J, Llaneras J, et al. Effectiveness and safety of ombitasvir, paritaprevir,ritonavir\$pm\$dasabuvir\$pm\$ribaviri $\mathrm{n}$ : An early access programme for Spanish patients with genotype 1/4 chronic hepatitis $\mathrm{C}$ virus infection. Journal of Viral Hepatitis 2016; 24:226237. doi: 10.4254/wjh.v9.i33.1239.

29. Schnell G, Tripathi R, Beyer J, Reisch T, Krishnan $\mathrm{P}, \mathrm{Lu} \mathrm{L}$, et al. Hepatitis C virus genotype 4 resistance and subtype demographic characterization of patients treated with ombitasvir plus paritaprevir/ritonavir. Antimicrobial Agents and Chemotherapy 2015; 59:6807-6815. doi: 10.1128/AAC.01229-15.

30. Morisawa N, Koshima Y, Kuriyama S, Matsuyama M, Hayashi N, Satoh J, et al. Effectiveness of a fixed combination formula of ombitasvir/paritaprevir/ritonavir for hepatitis $\mathrm{C}$ virus infection in patients on maintenance hemodialysis. Nephrology 2017; 22:562-565. doi: 10.1111/nep.13011.

31. Ferenci P, Bourgeois S, Buggisch P, Norris S, Curescu M, Larrey D, et al. Real-world safety and 
effectiveness

of

ombitasvir/paritaprevir/ritonavir\$pm\$dasabuvir\$। pm\$ribavirin in hepatitis $\mathrm{C}$ virus genotype 1-and 4infected patients with diverse comorbidities and comedications: A pooled analysis of postmarketing observational studies from 13 countries. Journal of Viral Hepatitis 2019. doi:10.1111/jvh.13080.

32. Flisiak R, Janczewska E, WawrzynowiczSyczewska M, Jaroszewicz J, Zarębska-Michaluk $\mathrm{D}$, Nazzal K, et al. Real-world effectiveness and safety ombitasvir/paritaprevir/ritonavir\$pm\$dasabuvir\$। pm\$ribavirin in hepatitis C: AMBER study. Alimentary Pharmacology \& Therapeutics 2016; 44:946-956. doi:10.1111/apt.13790.

33. Lucejko M, Parfieniuk-Kowerda A, Flisiak R. Ombitasvir/paritaprevir/ritonavir plus dasabuvir combination in the treatment of chronic HCV infection. Expert Opinion on Pharmacotherapy 2016; 17:1153-1164. doi: 10.1080/14656566.2016.1176143.

34. Poordad F, Hezode C, Trinh R, Kowdley KV, Zeuzem S, Agarwal K, et al. ABT-450/rombitasvir and dasabuvir with ribavirin for hepatitis C with cirrhosis. New England Journal of Medicine 2014; 370:1973-1982. doi: 10.1056/NEJMoa1402869.

35. Feld JJ, Moreno C, Trinh R, Tam E, Bourgeois S, Horsmans $\mathrm{Y}$, et al. Sustained virologic response of $100 \%$ in HCV genotype $1 \mathrm{~b}$ patients with cirrhosis receiving ombitasvir/paritaprevir/ $\mathrm{r}$ and dasabuvir for 12 weeks. Journal of Hepatology 2016; 64:301-307. doi: 10.1016/j.jhep.2015.10.005.

36. Backus LI, Belperio PS, Shahoumian TA, Loomis TP, Mole LA. Comparative effectiveness of ledipasvir/sofosbuvir\$pm\$ribavirin ombitasvir/paritaprevir/ritonavir+ dasabuvir\$pm\$ribavirin in 6961 genotypes 1 patient treated in routine medical practice. Alimentary Pharmacology \& Therapeutics 2016; 44:400-410. doi:10.1111/apt.13696.

37. Butt AA, Yan P, Simon TG, Abou-Samra A-B. Effect
Paritaprevir/Ritonavir/Ombitasvir/Dasabuvir and Ledipasvir/Sofosbuvir regimens on survival compared with untreated hepatitis C Virus-infected persons: results from ERCHIVES. Clinical Infectious Diseases 2017; 65:1006-1011. doi: 10.1093/cid/cix364. 